\title{
STABILITY OF ANGLE-PRESERVING MAPPINGS ON THE PLANE
}

\section{JACEK CHMIELIŃSKI}

Abstract. We prove that for the mappings of the plane the property of preserving the angle between vectors is stable. We apply this result to prove some kind of stability of the Wigner equation on the plane.

Mathematics subject classification (2000): 39B82, 81Q05.

Key words and phrases: Wigner equation, stability.

\section{REFERENCES}

[1] J. CHMIELIŃSKI, On a singular case in the Hyers-Ulam-Rassias stability of the Wigner equation, J. Math. Anal. Appl. 289, (2004), 571-583.

[2] J. ChMielińsKi AND S.-M. Jung, The stability of the Wigner equation on a restricted domain, J. Math. Anal. Appl. 254 no. 1 (2001), 309-320.

[3] D. H. HyERS, G. IsAC AND TH. M. Rassias, Stability of Functional Equations in Several Variables, Progress in Nonlinear Differential Equations and Their Applications vol. 34, Birkhäuser, Boston-BaselBerlin, 1998.

[4] S.-M. Jung, P. K. SAHOO, Superstability of the generalized orthogonality equation on restricted domains, Proc. Indian Acad. Sci., (Math. Sci.), 114, 3 (2004), 253-261.

[5] S. M. Ulam, Problems in Modern Mathematics (Chapter VI, Some Questions in Analysis: $\S 1$, Stability), Science Editions, John Wiley \& Sons, New York, 1964.

[6] E. P. WIGNER, Gruppentheorie und ihre Anwendungen auf die Quantenmechanik der Atomspektren, Friedr. Vieweg und Sohn, Braunschweig, 1931. 